\title{
Research on Teaching Reform of Accounting Computerization Course Based on the Concept of "Flipped Classroom"
}

\author{
Xia Su \\ Hebei Youth Administrative Cadres College, Hebei, Shijiazhuang, 050031
}

Keywords: Flip Classroom, Concept, Accounting Computerization, Course Teaching, Teaching Reform

\begin{abstract}
With the development of the times, the introduction of new educational ideas and conducive to people's learning related to cultural knowledge, "flip classroom" is a new educational model in recent years, emphasizing the student-centered education activities to expand the students learning perspective, improve learning interest. The traditional accounting computerization curriculum has many deficiencies in the examination, and the new educational model is used in computerized courses to develop new teaching ideas, which will help students understand and master the relevant knowledge theory concepts to a certain extent, the "flip classroom" concept facilitates the reform of computerized accounting courses.
\end{abstract}

\section{Introduction}

The accounting computerization course occupies an important position throughout the accounting profession. At present, the teaching process of accounting computerization course in accounting profession in colleges and universities is usually through the teaching and learning mode of teachers, but the mode of education is that the teacher's center and students cannot be autonomous learning, but forced to receive education, spoon-fed learning model is easy for students to wear tired of the emotions and lead to the final learning results are basic knowledge is not strong, the actual operational capacity is weak cannot achieve the social enterprise of talent claim. The use of "flip classroom" concept, the current accounting computerization course to teach the process of the existing problems, to improve students to take the initiative to accept the basic knowledge of computerized accounting and proficiency in accounting computerization of the actual operation, to avoid theory and practice are out of touch with each other. How to use the "flip classroom" concept and the accounting computerization curriculum reform is particularly important.

\section{The Current Situation of Accounting Computerization Teaching in Colleges and Universities}

Chinese institutions of higher learning have set up accounting courses to cultivate the relevant accounting personnel to support the construction of the cause of socialism. At present, the teaching of computerized courses in accounting profession in our country mainly adopts the traditional education mode, teaching theory is that students listen, do not participate in the actual interaction, resulting in the efficiency of learning is low. The traditional teaching model mainly has the following drawbacks:

Teaching Objectives and Actual Phase out of Line. The purpose of this course is to cultivate students' mastery of practical operation ability and become a high-quality and highly skilled accounting personnel with computerized thought to meet the needs of modern social talents. However, the traditional teaching to take the theory of teaching and related practical ability to separate education methods, attention to the acquisition of accounting qualification, without paying attention to the practical ability of students to master and familiarity with the relevant concepts.

Set the teaching objectives are often too high to combat the enthusiasm of students to learn, and 
some institutions of higher learning and even the basic operation of the platform are limited, which caused the students to master the theory, and the relevant educational concepts are not familiar with the situation, lack of ability to respond to sudden problems, do not meet the needs of enterprises in the community on the talent.

Set up Hours Limited and Poor Training Results. Colleges and universities teaching mode is too traditional, set up computer hours of computerization set up tight, a lot of professors to explain only to finish the lesson, leaving a student thinking time is short, student participation is small; due to limited hours lead to student learning and lack of mastery. Affected by the impact of traditional education, a lot of institutions of higher learning focus on the concept of knowledge to teach, the emphasis on training is not enough, resulting in less practical experience of students, lack of operational skills and experience.

Teachers teaching process, pay attention to teaching, case analysis and multimedia cover, some institutions of higher learning did not take school-enterprise cooperation model, for the community on the accounting practitioners of the requirements of the concept of fuzzy cannot keep up with the trend of the times. Students are only one-sided acceptance of the relevant concepts of learning, rather than the actual operation of this understanding of its working principle. And because of limited hours, many teachers are only teaching the focus of the examination, for other details of the problem to deal with fuzzy.

Set up Relatively Simple Course and Lack of Fun. The classroom becomes the main battlefield for students to learn computerized accounting courses. Students learn the knowledge of computerized courses in the classroom, confined to the classroom. Many of the institutions of higher learning to set up the main subjects of accounting is the "basic accounting", "financial regulations and accounting professional ethics", and finally is the "accounting computerization" knowledge of learning.

There are differences between students, individual cultural quality is different, the relevant accounting is not the same understanding of the concept, which led to a lot of students cannot keep up with the course, gradually lost the fun of learning the course. And the traditional knowledge of the classroom is too boring, a lot of students easy to learn in the process of God, class attention cannot be concentrated, which led to students stratification serious.

Students' Training Time is Limited. Students master the accounting computerization of the focus on the teacher in the classroom teaching, rather than the actual operational capacity, this is a lot of institutions of higher learning accounting for the professional disciplines using the teaching model. Do not pay attention to the arrangements for training classes, school leaders do not attach importance to, but rather a lot of students cannot cause enough attention.

This phenomenon is not conducive to the students of the specific knowledge of the master is limited to the mastery of theoretical knowledge, the actual operation process does not understand, the lack of relevant practical ability, does not meet the social needs of accounting personnel.

The School's Assessment Mechanism is Old. Now a lot of institutions of higher learning to take the concept of accounting computerized knowledge to master, very little specific operational capacity to assess, so that the result is the ability to learn dive, students appear partial phenomenon, to measure the results the quality of the students, so taught out of the accounting computerized talent is only the work of the machine, but no practical ability to adapt. Modern school assessment mechanism should be consistent with the trend of the times, not only for the student accounting computerization of the theoretical knowledge of the study, but also should focus on training, on time or irregularly sampled, timely adjustment of teaching mode. For the school's assessment mechanism should be combined with the modern learning model of the new features of the assessment of the original problem on the degree.

\section{The Status Quo of Using the "Flip Classroom"}

The concept of "flip classroom" originated in the West, but with the introduction of this concept, and the combination of Chinese domestic education model, the formation of a new way of education changes, this is the result of the times, the same traditional teaching model is not suitable 
for the development of today's society, the need to assess the overall quality of students, rather than one-sided theoretical results.

"Flipped Classroom" simply is the traditional classroom tasks and homework combined with each other, triggering a revolution in traditional educational methods. In the traditional mode of education, teachers and students must be taught in the same space, teaching for a long time, students are forced to accept, students are the subject of acceptance of knowledge, and because of the boring accounting science, the use of "flip classroom" concept It is very necessary to carry out the reform.

The use of "flip classroom" concept of accounting computerized course teaching, can promote students to computerized knowledge of learning confidence, the current domestic network of several educational platform to build students to become the center of the classroom need to participate in the process of education come, the teacher plays the role of mentor.

But the current domestic "flip classroom" and did not get a wide range of respected, because the relevant educational personnel factors, there is the regional differences, the quality of students lead to "flip classroom" to implement the difficulty of increasing. College students are all selected by the layers of high-quality students, but by the traditional concept of education, independent learning consciousness is not, the teacher is still the center of the classroom to increase the change of this situation has an important positive role.

\section{How to Use the Concept of "Flip Classroom" to Reform Accounting Computerized Curriculum}

The traditional educational classroom cannot meet the desire of people to learn knowledge now, "a teacher, explain to multiple students" model moved from the school to the network, the establishment of a reasonable assessment mechanism, so that students on the "flip classroom" Understand the implementation of the relevant teaching assessment standards, so that students in the process of learning the team to understand the problem.

The Scientific Construction of Curriculum Assessment Mechanism System. "Flip classroom" concept for the accounting computerization curriculum reform, should pay special attention to the assessment mechanism for computerized learning students to adopt a reasonable assessment method. Institutions of higher learning accounting computerization courses are mostly used examination system for students' usual habits do not pay attention, resulting in students do not understand the actual operating ability, training as "paper" talent.

Colleges and universities to take "flip classroom" concept of computerized knowledge of the transfer, should pay attention to the quality of individual, accounting computerized course teaching reform should pay attention to curriculum reform to adapt to the academic and industrial development needs for the community high-quality skilled personnel to hide the needs of the cause of building socialism.

The student's assessment mechanism, scaled to the overall quality of the assessment, usually results, mid-term results, as well as the end of the relevant assessment of the concept of change. Students in the learning process should establish a healthy and progressive learning philosophy master the basic knowledge of computerized accounting and practical operational capacity.

It will be part of the examination to refine the capacity of self-learning assessment, thinking ability assessment, to solve the problem of random response ability assessment, improve the overall quality of students, a professional accounting computerized talent.

The Importance of Interactive Issues in the Classroom. The concept of "flip classroom" mainly focuses on student-centered, teacher-oriented talent to promote students in the process of learning computerized course of learning, students through collective discussion, group discussion, typical case analysis, active and classmates and teachers to ask for learning.

Teachers should actively guide, so that students into the subconscious of self-learning to the existing problems in-depth understanding and cultural exchanges.

Create a Number of Independent Learning Platforms. With the development of society, the improvement of the level of science and technology, the traditional educational model cannot meet the importance of modern culture communication mode, and consult with the exchange mode of 
modern culture, and more emphasis on the understanding of traditional educational ideas. The main part of the classroom is mainly focused on the transformation of the classroom form, and gradually changes the mode of teaching. In the traditional classroom mode, "teaching" guides the "learning", promote the formation of students as the education center. Students become the main body of teaching activities, and teachers are teaching the main body is mainly on the students in the independent study of computerized accounting knowledge of the time to explain the problem, increase the confidence of students to learn. To ensure the effectiveness of learning to help students consolidate theoretical knowledge and practical operational capacity.

Achieve Teaching Content and Formal Interaction. "Turn the classroom" under the guidance of the concept, the curriculum should be a compact development, making the classroom atmosphere, classroom content is rich. To achieve the interactive content of students and teachers more, accounting computerization course teaching process should be in the original teaching concept of memory design innovation, to avoid the learning process of students boring pay attention to training and theory is only a combination.

Teachers in the whole student's learning process, as the role of assistants, the class to the students, to guide students to explain the typical case, the lack of students in the relevant supplement, in order to deepen the mastery of the theoretical knowledge of students. Urge students to establish an independent mode of thinking.

\section{References}

[1] Wang Haisheng, Wang Zhuqiang. Teaching reform of accounting computerization course based on the concept of "flip classroom" [J]. Journal of Zunyi Normal University, 2014,03: 120-123.

[2] An Empirical Study on the Reform of Micro - course Reform in the Teaching of Practical Courses - A Case Study of Accounting Computerization in Higher Vocational Colleges [J]. Journal of Henan Finance \& Taxation University Journal of Henan Finance \& 06: 61-64.

[3] Wang Haisheng, Wang Zhuqiang.Study on the construction of accounting computerized course assessment system based on "flip classroom"[J]. Journal of Anhui Business College of Vocational Technology (Social Science Edition), 2016, 02: 73-76

[4] Wei Lu, Zhao Jinfang. Research on the teaching model of flip teaching based on Muji - Taking "accounting computerization" course as an example[J]. Journal of Changsha University of Science and Technology (Social Science Edition), 2016, 03: 134

[5] Ding Mei. Based on the "flip classroom" concept of adult accounting teaching model reform "basic accounting" course as an example[J]. Education and Teaching Forum, 2015, 41: 125-127.

[6] Long Qi any. Based on the concept of flip school "accounting computerization" course teaching exploration and practice[J]. New curriculum research (mid-term), 2015, 11: 56-57

[7] Long Qi Ren. Turn the classroom under the concept of accounting computerized teaching the main constraints of the analysis [J]. Intelligence, 2015, 34: 24-25.

[8] Wang Yao. "Flip classroom" concept based on the accounting of computerized course teaching reform[J]. Contemporary education practice and teaching research, 2016, 08: 7 